\title{
Naked and Unashamed: Investigations and Applications of the Effects of Naturist Activities on Body Image, Self-Esteem, and Life Satisfaction
}

\author{
Keon West ${ }^{1}$
}

Published online: 21 January 2017

(C) The Author(s) 2017. This article is published with open access at Springerlink.com

\begin{abstract}
Body image dissatisfaction is a serious, global problem that negatively affects life satisfaction. Several claims have been made about the possible psychological benefits of naturist activities, but very little empirical research has investigated these benefits or any plausible explanations for them. In three studies-one large-scale, cross-sectional study $(n=849)$, and 2 prospective studies $(\mathrm{n}=24, \mathrm{n}=100)$ this research developed and applied knowledge about the possible benefits of naturist activities. It was found that more participation in naturist activities predicted greater life satisfaction-a relationship that was mediated by more positive body image, and higher self-esteem (Study 1). Applying these findings, it was found that participation in actual naturist activities led to an increase in life satisfaction, an effect that was also mediated by improvements in body image and selfesteem (Studies 2 and 3). The potential benefits of naturism are discussed, as well as possible future research, and implications for the use of naturist activities.
\end{abstract}

Keywords Nudity $\cdot$ Body image $\cdot$ Self concept $\cdot$ Quality of life

\section{Introduction}

Dissatisfaction with one's body is a serious, international problem (Al Sabbah et al. 2009). Large-scale surveys in countries as diverse the United States (Liechty 2010), Brazil (Pelegrini and Petroski 2010) and Finland (Ålgars et al. 2011) find high rates of unhappiness with one's body, weight control behaviours, and symptoms of body image distortion, even among non-overweight participants. In naturist activities, one is communally naked in the company of non-intimate others who typically have non-idealised bodies

Keon West

keon.west@gold.ac.uk

1 Department of Psychology, Goldsmiths, University of London, Lewisham Way,

London SE14 6NW, UK 
(Green 2001). These activities may reduce dissatisfaction with one's body through exposure to non-idealised bodies (Re et al. 2011), or positive (or even neutral) feedback about one's own body (Herbozo and Thompson 2006). This current research investigates and applies these potential benefits of naturist activity and is the first to test a specific mediated model of the effect of naturism on body image, self-esteem and life satisfaction.

\section{Body Image, Self-Esteem and Life Satisfaction}

Prior research suggests that negative body image in both women and men stems from pressure to achieve unrealistic ideals of attractiveness (McCreary and Sasse 2000; StriegelMoore et al. 1986). Frequent exposure to media-based standards of attractiveness, which are often unattainably thin (for females) or muscular (for males), leads to a more negative perception of one's own body (Agliata and Tantleff-Dunn 2004; Engeln-Maddox 2005; Grabe et al. 2008).

One's body-concept is an important aspect of one's overall self-concept, and a wellestablished body of research demonstrates the relationship between body-image and selfesteem (e.g., Herbozo and Thompson 2006; Kostanski and Gullone 1998; Olivardia et al. 2004). Some of this research specifically supports a causal relationship from body image to self-esteem, rather than the reverse (Hesketh et al. 2004). Similarly, a well established body of prior research provides ample evidence of the relationship between self-esteem and life satisfaction (e.g., Acun-Kapikiran et al. 2014; Kang et al. 2003; Navarro et al. 2014; Oishi et al. 1999; Paradise and Kernis 2002; Park et al. 2014). This research is largely cross-sectional (rather than experimental or longitudinal) and thus cannot confirm the causal direction of this relationship. However, the direction of effects from self-esteem to life satisfaction has been supported statistically by structural equation modeling or other analyses of mediation effects (see, e.g., Acun-Kapikiran et al. 2014; Kang et al. 2003; Navarro et al. 2014).

If positive body image improves self-esteem, which in turn may affect life satisfaction, it is important to bolster or improve one's body image. Prior research his investigated methods of doing this, such as exposure to bodies that differ from idealised images. For example, Re et al. (2011) found that brief exposure to heavier bodies increased participants' preference for heavier looking individuals. Similarly, Swami (2015) found that women reported more positive body image after taking part in a life drawing session: an event in which participants produce drawings of the human figure by observing a nude model present in the room. However, a potentially underused strategy might be found in naturist activities, which could offer a low-cost, widely available solution to the problem of body dissatisfaction.

\section{Possible Psychological Benefits of Naturism}

Naturism (or nudism) is a multi-faceted concept that varies both geographically and over time; the primary element of naturist or nudist subculture is going without clothes. However, this can have complex interactions with other elements of the dominant cultures in which it is based (Smith 1980), or with other concerns, such as the potential for eroticism (Smith and King 2009). Naturism and nudism may also have a variety of political meanings (Cooper 2011); hence, some people may be willing to take part in public nudity, 
but hesitant to identify themselves as naturists or nudists (Ipsos-Mori 2011). For these reasons, it is difficult to identify a single, universal definition of naturism. However, many of the largest contemporary national and international naturist organisations define naturism as going without clothes in the presence of non-intimate others, or being nude in public without the intention of being sexually stimulating (British Naturism: What is Naturism? 2015; Deschenes 2016).

Across multiple countries, attitudes toward public nudity appear to be improving (CarrGomm 2012). Large-scale, representative surveys conducted in 2001 and 2011 show that about a quarter of all Britons have taken part in some naturist activity (e.g., nude sunbathing), and this number is likely growing (Ipsos-Mori 2011). Other signs of internationally softening attitudes toward public nudity include the rising popularity of the World Naked Bike Rides - events where hundreds or thousands of people cycle naked through cities to call attention to the vulnerability of cyclists (Dieleman 2008; Pucher et al. 2011).

Initially, there was significant concern that naturism either reflected or resulted in negative psychological effects (Negy 2004), particularly for children (Okami 1995; Smith and Sparks 1986). However, the empirical research on naturism and public nudity failed to support these assumptions. Oleinick et al. (1966) found no relationship between exposure to nudity in childhood and later psychiatric symptomology. Lewis and Janda (1988) found a positive association between exposure to nudity early in life and willingness to engage in casual sex, but no associations with any other measure of sexual or emotional adjustment. In an 18-year longitudinal study Okami et al. (1998) found no effects of exposure to parental nudity on sexual activity during adolescence, teenage pregnancy, contracting sexually transmitted diseases, or antisocial behaviour such as shoplifting. Indeed, exposure to parental nudity was associated with less usage of recreational drugs and higher levels of self-acceptance. Given the apparent lack of negative effects, it was perhaps unsurprising that the potential positive effects of naturism began to be considered.

Naturist organisations themselves claim that participation in naturist activities should lead to improvements in body image, self-esteem and overall life satisfaction (British Naturism: What is Naturism? 2015; see also O'Reilley 2015). However, very little research has empirically investigated these claims. While some qualitative reports suggest that naturism may reduce self-consciousness (Green 2001), and a few quantitative studies have found an association between positive body image and naturist identity (Story 1979, 1984) or pro-nudity attitudes (Negy and Winton 2008), no studies to date have investigated the effects of actual naturist behaviour. This is important because identification and behaviour may not always be aligned; many more people take part in some clothing-optional activity than would identify themselves as naturists or nudists (Ipsos-Mori 2011).

\subsection{Why Should Naturism Have Positive Psychological Effects?}

The model suggested by naturist organisations is one in which naturist activities lead to an improvement in body image, which should in turn lead to an improvement in self-esteem and thus to increased life satisfaction (British Naturism: What is Naturism? 2015; O'Reilley 2015). As discussed above, the effects of body image on self-esteem and the relationship between self-esteem and life satisfaction have been extensively supported by prior research (Kang et al. 2003; Kostanski and Gullone 1998; Molloy and Herzberger 1998; Oishi et al. 1999). Thus, the aspect of the model that remains to be tested and explained is the proposed positive effect of naturism on body image.

As discussed above, current models suggest that negative body image in both women and men derives from exposure to, and pressure to achieve, unrealistic ideals of 
attractiveness (Agliata and Tantleff-Dunn 2004; Engeln-Maddox 2005; Grabe et al. 2008; McCreary and Sasse 2000; Striegel-Moore et al. 1986). However, this effect can be countered by exposure to bodies that differ from these idealised images (Re et al. 2011; Swami 2015). Hence, naturist activities, in which one is able to observe a wide variety of bodies that differ from idealised images, should also be able to counteract these negative effects and promote a more realistic standard of physical attractiveness.

Alternatively, however, naturism may have positive effects due to feedback about one's own body. Abraczinskas et al. (2012) found that negative weight-related and eating-related comments from one's parents can affect one's drive for thinness and encourage bulimic symptomatology in teenagers. However, in a dominant atmosphere of negative feedback about one's body, positive or even neutral feedback may lead to improved body image (Herbozo and Thompson 2006; Mclaren et al. 2004). Naturist activities, in which individuals spend time naked in the company of non-intimate others, also involve being seen naked by a large number of people in a relatively non-judgemental context, which might lead to less dissatisfaction with one's body. To date, however, neither of these two possible explanations for naturism's effects (seeing others vs. being seen by others) has been explored empirically.

\section{Current Research}

Despite the positive claims of naturist organisations, there is a gap in the available empirical research concerning the possible psychological benefits of naturism and the mechanisms explaining these benefits. This current research fills this gap by investigating a specific proposed model in which naturist activity is associated with greater life satisfaction, and in which this relationship is mediated in turn by more positive body image and higher self-esteem. Furthermore, this research also investigates whether two specific aspects of naturism (i.e., seeing others vs. being seen by others) are associated with more positive body image. Finally, having tested a model of naturism's effects, this knowledge is applied at two genuine naturist activities to investigate whether subsequent improvements in body image, self-esteem and life satisfaction occur.

\section{Study 1}

This large, cross-sectional study investigated a model of the effects of naturist activity on life satisfaction, mediated by higher body image and self-esteem. Explanations for naturism's effects on body image (seeing others vs. being seen) were also explored.

\subsection{Method}

\subsubsection{Participants and Design}

Eight hundred and forty-nine members of the British public were recruited via word-ofmouth and advertisements posted on various Internet forms to take part in this research. Of these participants, $739(87 \%)$ were male, $94(11 \%)$ were female and $16(.02 \%)$ did not identify their gender or reported a non-binary gender. The mean age was 57.19 , with a standard deviation of 12.00. Ethnically, $831(98 \%)$ identified as White, $3(.4 \%)$ as East 
Asian, $2(.2 \%)$ as South Asian, 0 as Black, and 13 (2\%) as "other"; 405 (54\%) identified themselves as having no religion, 366 (43\%) identified as Christian, 0 identified as Muslim, $74(9 \%)$ identified themselves as "other" and $4(.5 \%)$ declined to identify a religion; 702 $(83 \%)$ identified as heterosexual, $39(5 \%)$ as gay, $94(11 \%)$ as bi-sexual, and $14(2 \%)$ as "other".

All participants completed the study online using a computer and Qualtrics survey completion software. Participants were told that the study investigated the association between social activities and well-being, but were not made aware of any of the specific hypotheses. All participants indicated whether they had ever taken part in any naturist activities, and if yes, when they began doing so and how frequently they did so. All participants completed measures of body image, self-esteem, and life satisfaction. At the end of the survey participants were thanked and fully debriefed. All those who completed the survey were offered the chance to win $£ 150$ in a prize draw. Only participants who completed the questionnaire were included in the prize draw or the analyses.

\subsubsection{Measures}

To assess participation naturist activities, participants were asked to indicate (yes vs. no) whether they had ever taken part in "in clothes-free activities (i.e., activities in which you have been fully or partially undressed outdoors and/or in the company of other people (other than your close family or romantic partner)." The language of this question deliberately focused on participants' behaviour and avoided the labels "nudist" and "naturist". If a participant responded yes to this initial question, they were asked to indicate (using the year and the month) when they had started participating in these activities and how many of these activities they did in a typical year. Subtracting the date at which the participant started taking part in naturist activities from the date at the end of data collection produced a measure of length of time (in years) doing naturist activities.

As both the time spent doing naturist activities and the frequency of these activities were important for this research, the product of the time spent doing naturist activities (in years) and frequency of naturist events per year was used as the index of naturist activity. For example, if a participant reported taking part in naturist activities for 2 years, and typically taking part in 3 naturist activities per, this participant would have an index score of $(2 \times 3=) 6$. This approach has been successfully used in prior social-psychological research (e.g., Evans-Lacko et al. 2013; Taschler and West 2016; Voci and Hewstone 2003; West and Hewstone 2012; West et al. 2014). Participants who indicated that they had never taken part in any naturist activity were assigned scores of 0 for both the number of years spent taking part in naturist activities and the number of naturist activities per year (thus, they necessarily had index scores of 0 as well).

Positive body image was measured by the 13-item Body Appreciation Scale (Avalos et al. 2005). Using 7-point Likert scales $(1=$ Strongly Disagree, $7=$ Strongly Agree $)$ participants indicated their agreement with the following statements: "I respect my body", "I do not feel good about my body" (reversed), "On the whole, I am not satisfied with my body" (reversed), "Despite its flaws, I accept my body for what it is", "I feel that my body has at least some good qualities", "I take a positive attitude towards my body", "I am attentive to my body's needs", "Despite its imperfections I still like my body", "My self worth is independent of my body shape or weight", "I focus a lot energy being concerned with my body shape or weight" (reversed), "My feelings toward my body are positive, for the most part", "I engage in healthy behaviours to take care of my body", "I do not allow 
unrealistic images presented in the media to affect my attitudes toward my body" $(\alpha=.84)$.

Self-esteem was measured with the 10-item Rosenberg Self-Esteem Scale (Rosenberg 1965, more recently used by Ashburn-Nardo et al. 2007). Using 4-point Likert scales ( 1 = Strongly Disagree, $2=$ Disagree, $3=$ Agree, $4=$ Strongly Agree $)$ participants indicated their agreement with the following statements: "On the whole, I am satisfied with myself", "At times, I think I am no good at all" (reversed), "I feel that I have a number of good qualities", "I am able to do things as well as most other people", "I feel I do not have much to be proud of" (reversed), "I certainly feel useless at times" (reversed), "I feel that I'm a person of worth", "I wish I could have more respect for myself" (reversed), "All in all, I am inclined to think that I am a failure" (reversed), "I take a positive attitude toward myself" $(\alpha=.78)$.

Overall life satisfaction was measured with the 5-item Satisfaction with Life Scale (Diener et al. 1985). Using 7-point Likert scales $(1=$ Strongly Disagree, $7=$ Strongly Agree) participants indicated their agreement with the following statements: "In most ways my life is close to ideal", "The conditions of my life are excellent", "I am satisfied with my life", "So far, I have gotten the important things I want in life", "If I could live my life over, I would change almost nothing" $(\alpha=.91)$.

To distract participants from the true purpose of the study, a number of filler items were included concerning relationships between males and females, gender norms and sexual activity in general. The order of presentation of the measures was also counter-balanced across participants. After completing all the measures, participants were thanked and fully debriefed.

\subsection{Results}

\subsubsection{Preliminary Analyses}

Descriptive statistics can be seen in Table 1. In total 861 people started the survey. Most of the scales used in the survey contained some reversed items. For example, the Rosenberg Self-Esteem Scale contained the items "On the whole I am satisfied with myself" (nonreversed item) and "At times I think I am no good at all" (reversed item). If a participant gave the same response to the reversed and non-reversed items throughout the scale, this was marked as an incorrect completion and this participant's data were discarded. Twelve

Table 1 Descriptive statistics of all variables used in Study 1

\begin{tabular}{lllrrr}
\hline & Min & Max & Median & Mean & Standard deviation \\
\hline Age & 16 & 90 & 59.00 & 57.19 & 12.10 \\
Years doing naturist activities & 0 & 65.17 & 24.83 & 23.65 & 16.48 \\
Naturist activities per year & 0 & 365 & 17.00 & 36.75 & 62.89 \\
Index of naturist activity & 0 & $21,900.00$ & 270.00 & 1151.11 & 2662.10 \\
Positive body-image & 2.46 & 7 & 5.85 & 5.70 & .81 \\
Self-esteem & 1.20 & 4 & 3.30 & 3.24 & .53 \\
Life satisfaction & 1.00 & 7 & 5.20 & 4.87 & 1.38 \\
\hline
\end{tabular}


participants (10 men and 2 women) were discarded for this reason, leaving 849 participants for analysis.

Overall, most participants (805 or $95 \%$ ) indicated that they had taken part in naturist activity at least once in their lives; participants also indicated that they took part in a mean of 36.75 naturist events per year. However, this number may be misleadingly high. Fifty per cent of participants took part in 17 or fewer naturist activities per year, suggesting that these participants were not ardent naturists, but rather people who would occasionally take part in clothing-optional activities. Furthermore, the phrasing of the question, which asked participants whether they had ever "been fully or partially undressed outdoors and/or in the company of other people (other than [their] close family or romantic partner)", was very inclusive, and may have increased the number of positive responses. For example, each topless trip to a beach would count as a separate activity. For those who had spent time taking part in naturist activities, overall they indicated that they started taking part a mean of 23.65 years ago, a value close to the median (24.83).

\subsubsection{Mediation Analyses}

Differences in the scales used to measure each of the variables could make statistical relationships between them difficult to interpret. For example, self-esteem was measured with a 4-point scale, body image and life satisfaction with 7-point scales, and the index of naturist activity had a minimum of 0 ( 0 naturist activities per year $\times 0$ years $)$ and a maximum of 21,900 (365 naturist activities per year $\times 60$ years). To increase clarity of presentation, all variables were normalised so that they had a mean of 0 and a standard deviation of 1 (as previously done by Fryer Jr. and Levitt 2004; Strand 2012). These standardized variables are used in the subsequent mediation analyses and correlations between these standardized variables can be seen in Table 2 .

It was hypothesised that naturist activity would predict higher life satisfaction and that this relationship would be mediated in turn by more positive body image and higher selfesteem. These relationships were investigated using PROCCESS macros (Model 6, with a 95\% confidence interval based on 10,000 bootstrap samples; Hayes 2009). Age, ethnicity, religion and sexual orientation were included as covariates in these analyses to rule out possible alternative explanations for our findings (and also, in the case of age, because of a possible confound of the measure of naturist activity, which incorporated a measure of time in years). The effects of gender are investigated more explicitly below. Only statistically significant relationships are reported.

The hypothesised mediated relationships were supported by the data; see Fig. 1. Naturist activity predicted more positive body image $(b=.08, p=.03)$, which in turn predicted higher self-esteem $(b=.50, p<.0001)$, and greater life satisfaction $(b=.08$,

Table 2 Correlations between standardised variables used in Study 1

1. Naturist activity

2. Body-image

3. Self-esteem

4. Life satisfaction
(1)

(2)

1

$.07 *$

.057

.011

1
$.51 * * * \quad 1$

$.36 * * * \quad .60 * * *$

(3)
(4)

$* p<.05 ; * * p<.01 ; * * * p<.001$ 


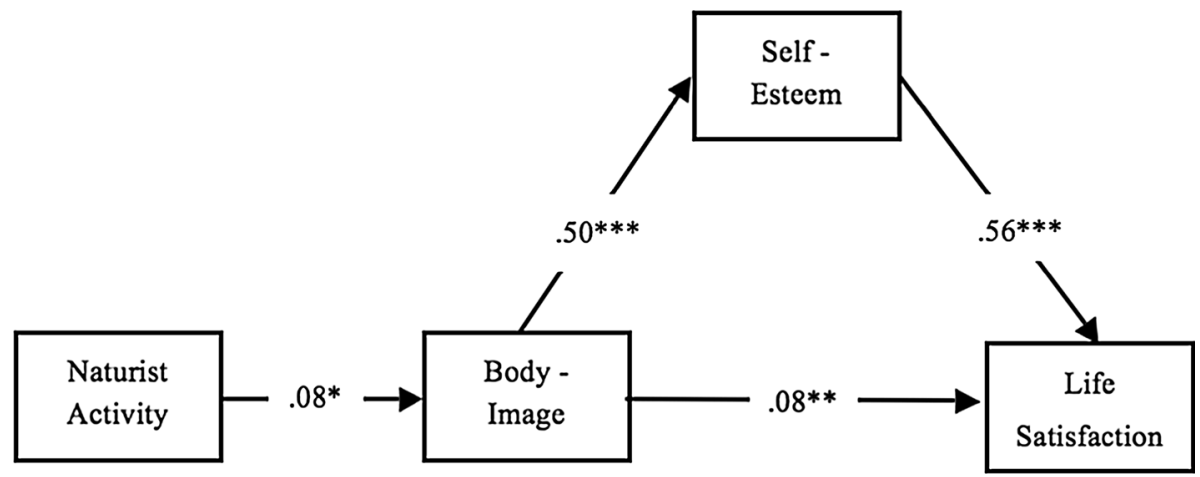

Fig. 1 Relationship between naturist activity and life satisfaction, mediated by body-image and self-esteem in Study 1. Note $* p<.05, * * p<.01, * * * p<.001$

Table 3 Mediators of the indirect relationship between naturist activity and life satisfaction in Study 1

\begin{tabular}{llcr}
\hline Mediators & Point estimate & LLCI & ULCI \\
\hline 1. Total indirect effect & .0379 & .0051 & .0830 \\
2. Via body-image & .0060 & .0005 & .0218 \\
3. Via body-image and self-esteem & .0213 & .0019 & .0495 \\
4. Via self-esteem & .0106 & -.0120 & .0387 \\
\hline
\end{tabular}

$p=.01)$. Higher self-esteem also predicted greater life satisfaction $(b=.56, p<.0001)$. The total indirect effect of naturist activity on life satisfaction was positive and significant; $L L C I=.0051, U L C I=.083$, point estimate $=.038$. All other indirect effects of naturist activity on life satisfaction can be seen in Table 3. This model accounted for $37 \%$ of the variance in participants' life satisfaction scores.

\subsubsection{Testing the Reversed Model}

While the data fit the proposed model well, it is necessary to test the reversed causal relationships. While it is possible that taking part in naturist activity causes improvements in body image, self-esteem, and life satisfaction, it is equally possible that people who are happier with themselves and their bodies are consequently more likely to take part in naturist activities. This reversed model-in which life satisfaction predicted naturist activity, mediated by higher self-esteem and more positive body image-was tested in the same manner as the proposed model: using PROCCESS macros (Model 6, with a 95\% confidence interval based on 10,000 bootstrap samples), and including age, ethnicity, religion and sexual orientation as covariates.

The data did not fit the reversed model as well as the original, proposed model. Life satisfaction predicted both higher self-esteem $(b=.60, p<.0001)$ and more positive body image $(b=.09, p=.01)$. Self-esteem also predicted more positive body image $(b=.45$, $p<.0001)$, but body image failed to predict participation in naturist activities $(b=.07$, $p=.10)$, as did self-esteem $(b=.05, p=.27)$ and life satisfaction $(b=-.04, p=.29)$. Furthermore, while the total indirect effect of life satisfaction on naturist activities was 
positive and significant $(L L C I=.01, U L C I=11$, point estimate $=.06)$, none of the specific mediated pathways was significant $(L L C I=-.007, U L C I=.07$, point estimate $=.03 ; L L C I=-.003, U L C I=.05$, point estimate $=.02 ;$ and $L L C I=-.0002$, $U L C I=.02$, point estimate $=.006)$.

\subsubsection{Effects of Gender}

This sample has a large ratio of male participants (739) to female participants (94). Furthermore, the men reported more positive body image than did the women; $M=5.71$ versus $M=5.45, t(831)=2.94, p=.003$. It was thus important to verify that the findings applied to women as well as to men. To this end, participants' gender was investigated as a potential moderator of the relationship between naturist activity and body image using PROCCESS macros (Model 1, 95\% C.I. 10,000 bootstrap samples). This moderation was not significant $\left(b_{\text {interaction }}=.08, p=.29\right.$ ). Furthermore, when only female participants were selected, naturist activity continued to significantly predict positive body image $(b=.15, p=.02)$.

\subsubsection{Different Levels of Naturist Activity}

It is notable that the proportion of participants in this sample who reported ever taking part in any clothes-free activity is much higher than the proportion reported in previous research (Carr-Gomm 2012; Ipsos-Mori 2011). Even accounting for the inclusive language of the survey, people who frequently take part in naturist activities are likely overrepresented in this sample, which raises questions about the generalizability of the findings to the broader public who do not frequently take part in naturist activities.

\subsubsection{Moderation Analyses}

To test whether these findings also applied to more representative participants (i.e., who did not frequently take part in naturist activities), all 849 participants were ranked from least participation in naturist activities (rank $=1$ ) to most participation in naturist activities (rank $=849$ ), and this rank was used as a moderator of the relationship between naturist activity and body image using PROCCESS macros (Model 1, 95\% C.I. 10,000 bootstrap samples).

This moderation was significant $\left(b_{\text {interaction }}=-.004, p=.0001\right)$. Furthermore, the pattern of results suggested that the association between naturism and positive body image was stronger for more representative participant samples. Examination of the moderated analysis revealed that the relationship between naturist activity and body image was strongest for participants who took part in the least naturist activities (i.e., those with the lowest rank numbers; $b=1.38, p<.0001$ ), weaker for those in the middle of the distribution $(b=.87, p<.0001)$ and weakest for participants who took part in the most naturist activities (i.e., those with the highest rank numbers; $b=.36, p=.0001$ ).

\subsubsection{Median Split Analyses}

This pattern was also reflected in the correlations between naturist activity and body image, and the indirect effect of naturism on life satisfaction via body image and self-esteem. A median split divided participants into those who took part in fewer naturist activities and 
those who took part in more naturist activities. The subset of participants who took part in fewer naturist activities consisted of 365 men, 47 women, and 11 of unidentified or nonbinary gender (mean age $=55.31$ ). In this subset the mean number of naturist activities per year was 9.91, and the median was 6.00; the mean number of years since they first started taking part in naturist activities was 13.84 and the median was 9.08. When using only these participants $(n=423)$, the correlation between naturist activity and body image was somewhat stronger $(r=.12, p=.02)$, and naturist activity continued to directly predict more positive body image $(b=.13, p=.01)$, and to indirectly predict higher life satisfaction via higher body image and self-esteem $(L L C I=.01, U L C I=.08$, point estimate $=.04$ ).

Using this subset (i.e., those who took part in fewer naturist activities), I also found further support for the specific proposed model of relationships between variables. Using this subset of the participants, the reversed model (i.e., in which life satisfaction predicted naturist activity via self-esteem and body image) fit the data poorly despite the stronger correlation between naturist activity and body image. Body image weakly predicted participation in naturist activities $(b=.004, p=.01)$, but the total indirect effect of life satisfaction on naturist activities was not significant $(L L C I=-.002, U L C I=.002$, point estimate $<.0001)$.

By contrast, when using only the subset of participants whose naturist activity scores fell above the median $(n=424)$, the crucial relationships were no longer significant. The correlation between naturist activity and body image was not significant $(r=.02$, $p=.65)$. In the mediation model naturist activity did not directly predict more positive body image $(b=.01, p=.82)$, nor did it indirectly predict higher life satisfaction via higher body image and self-esteem $(L L C I=-.03, U L C I=.03$, point estimate $=-.002)$. In sum, both the moderation analyses and the median split analyses found that the relationship between naturism and positive body image was strongest for those participants who took part in fewer naturist activities. Indeed, it appears that the relationship no longer exists for individuals who pass a certain threshold number of naturist activities. This is similar to other psychological relationships like the association between income and subjective well-being which is strongest for poorer individuals, and weakens or ceases to apply above a certain level of income (Sengupta et al. 2012).

\subsubsection{Seeing or Being Seen?}

The final analyses investigated whether seeing others naked or being seen naked by others was more strongly related to positive body image. Two independent raters, unaware of the hypotheses, coded the free responses of the participants who had previously taken part in at least one clothes-free activity $(n=805)$. These raters quantitatively coded (i.e., $0=n o$, $1=$ yes) whether or not the participant had indicated benefiting from seeing a variety of other naked people (e.g., as one participant said, "Improves own body image, seeing others with normal, not perfect bodies"). The raters also quantitatively coded (i.e., $0=n o$, $1=$ yes) whether or not the participant had indicated benefiting from being seen naked by others without negative judgements (e.g., as one participant said, "no one judges you on your body shape which gives me more confidence"). All disagreements between raters were managed through discussion.

'Seeing others' scores and 'being seen' scores were used to predict participants' body image with PROCCESS macros (Model 1, 95\% C.I. 10,000 bootstrap samples). As before, age, gender, ethnicity, religion and sexual orientation were included as covariates. Seeing others naked predicted more positive body image $(b=.41, p=.008)$, though being seen by others 
did not predict more positive body image $(b=.15, p=.16)$. There was also an interaction between seeing others and being seen $\left(b_{\text {interaction }}=-.53, p=.04\right)$. However, being seen naked by others did not significantly predict positive body image whether participants reported benefiting from seeing others naked $(b=-.38, p=.11)$ or not $(b=.15, p=.16)$.

\section{Study 2}

Having found positive associations between naturist activity, body image, self-esteem and life satisfaction in Study 1, the following 2 studies apply these findings to real naturist activities.

\subsection{Method}

\subsubsection{Participants and Design}

Participants were 24 White British individuals (12 men, 12 women). Participants' age ranged from 22 to 67 years $(M=22, S D=14.47)$. A prospective design was employed; participants completed a questionnaire immediately before and after taking part in a real naturist activity.

\subsubsection{Procedure}

This study took advantage of a previously organised event-Bare all for Polar Bears - that took place at the Yorkshire Wildlife Park in Doncaster, UK. Participants at this event completed a naked stroll around the Yorkshire Wildlife Park to raise money in support of polar bear preservation (Mason 2015). Before the event, a research assistant sought permission from the organisers to solicit participation from the attendants. At the event, before participants disrobed, and if they provided written consent, they were then given a singlesided A-4 sheet of paper with the relevant measures presented in one of 3 randomised orders, a set of distractor questions, and a request for basic demographic information. Participants also indicated whether they had engaged in public nudity before (10 had not). The event itself lasted approximately $90 \mathrm{~min}$. After the event, immediately after redressing, participants were asked to compete the post-test questionnaire, which included the same measures and distractors as the pre-test questionnaire. All participants were also fully debriefed and entered into a $£ 50$ prize draw to reimburse them for their time and participation.

\subsubsection{Measures}

To facilitate quick and easy participation, the measures for this study were abbreviated versions of those used in Study 1. Participants indicated their responses to all measures on 45-mm lines, anchored by two extremes: Not at all, and Very much.

\subsubsection{Positive Body Image}

Both before and after the naturist activity, participants completed an abbreviated 8-item version $\left(\alpha_{\text {before }}=.90, \alpha_{\text {after }}=.88\right)$ of the 13-item Body Appreciation Scale (Avalos et al. 
2005). Participants indicated their agreement with the following statements: "I do not feel good about my body" (reversed), "I take a positive attitude towards my body", "I respect my body", "Despite its flaws, I accept my body for what it is", "On the whole, I am not satisfied with my body" (reversed), "Despite its imperfections I still like my body", "I am attentive to my body's needs", "My feelings toward my body are mostly positive". As indicated, two items were reverse-coded prior to analysis and an overall score was computed as the mean of all items such that higher scores indicated more positive body-image.

\subsubsection{Self-Esteem}

Participants also completed an abbreviated 4-item version $\left(\alpha_{\text {before }}=.82, \alpha_{\text {after }}=.66\right)$ of the 10-item Rosenberg Self-Esteem Scale (Rosenberg 1965). Participants indicated their agreement with the following statements: "I feel that I have a number of good qualities", "On the whole, I am satisfied with myself", "I feel I do not have much to be proud of" (reversed), "I feel that I'm a person of worth". As indicated, one item was reverse-coded prior to analysis and an overall score was computed as the mean of all items such that higher scores indicated higher self-esteem.

\subsubsection{Life Satisfaction}

Participants also completed an abbreviated 4-item version $\left(\alpha_{1}=.90, \alpha_{2}=.77\right)$ of the 5-item Satisfaction with Life Scale (Diener et al. 1985). Participants indicated their agreement with the following statements: "In most ways my life is close to ideal", "I am satisfied with my life", "If I could live my life over, I would change nothing". An overall score was computed as the mean of all items such that higher scores indicated greater life satisfaction.

\subsection{Results}

Descriptive statistics are reported in Table 4. Neither age nor gender predicted any of the dependent variables $(.08<$ all $p$ 's $<.99)$. Differences between pre-event and post-event scores were investigated using a repeated-measures multivariate analysis of variance with time (pre-naturist activity vs. post-naturist activity) as the independent variable and bodyimage, self-esteem and life satisfaction as dependent variables. This analysis is more conservative than using multiple paired-samples $t$ tests, which would not account for covariance between the dependent variables.

The expected multivariate effect of naturist activity was found, $F(3,21)=3.71$, $p=.028, \eta_{2}^{\mathrm{p}}=.35$. Compared to before the event, participants after the event reported more positive body-image, $M=3.00$ versus $M=3.29 ; F(1,23)=8.05, p=.009$,

Table 4 Means and standard deviations of all variables used in Study 2 according to time

\begin{tabular}{llc}
\hline & Pre-naturist activity & Post-naturist activity \\
\hline Body-image & $3.00(1.02)$ & $3.29(.91)$ \\
Self-esteem & $3.14(.98)$ & $3.43(.81)$ \\
Life satisfaction & $2.68(1.13)$ & $2.95(.97)$ \\
\hline
\end{tabular}

Standard deviations are shown in parentheses 
$\eta_{2}^{\mathrm{p}}=.26$, higher self-esteem, $M=3.14$ versus $M=3.43 ; F(1,23)=5.64, p=.026$, $\eta_{2}^{\mathrm{p}}=.20$, and greater life satisfaction $M=2.68$ versus $M=2.95 ; F(1,23)=6.76$, $p=.016, \eta_{2}^{p}=.23$. Subsequent analyses showed no significant interaction between time and either participant gender, $F(3,18)=.56, p=.65$, or previous naturist experience, $F(3,18)=.60, p=.63$. These results indicate that taking part in this event had positive psychological effects, and a possible interpretation is that the communal nudity during the event improved body-image, self-esteem and life satisfaction. However it is also possible that other aspects of the event (e.g., the fact that it was an altruistic event for charity) may have affected the dependent variables. Also, this study was limited by the small sample size (24), which was insufficient to test the whether the effect of the naturist activity on life satisfaction was mediated by changes in body image and self-esteem (Fritz and Mackinnon 2007). In view of this, Study 3 reports on a larger prospective study of the effects of naturist activity in a different setting that was not a charity event.

\section{Study 3}

\subsection{Method}

\subsubsection{Participants and Design}

Participants were 100 British individuals ( 83 men, 16 women, 1 who did not indicate a gender), of whom 96 were White. Participants' age ranged from 18 to 79 years $(M=45.36, S D=13.92)$. Again, a prospective design was employed; participants completed a questionnaire immediately before and after taking part in a naturist activity.

\subsubsection{Procedure}

This study took advantage of another previously organised event-Waterworld - that took place at a waterpark in Stoke-on-Trent, UK. Participants at this event spent $3 \mathrm{~h}$ naked at the waterpark with no requirement to take part in any specific activity. As before, a research assistant sought permission from the organisers to solicit participation from the attendants. At the event, before participants disrobed, and if they provided written consent, they were given a single-sided A-4 sheet of paper with the measures described above. After the event, immediately after re-dressing, participants were asked to compete the post-test questionnaire, which included the same measures and distractors as the pre-test questionnaire. All participants were also fully debriefed, though no reimbursement was offered for participation.

\subsubsection{Measures}

Study 3 used the same distractor measures and measures of positive body-image $\left(\alpha_{\text {be- }}\right.$ fore $\left.=.89, \alpha_{\mathrm{after}}=.89\right)$, self-esteem $\left(\alpha_{\text {before }}=.77, \alpha_{\mathrm{after}}=.78\right)$, and life satisfaction $\left(\alpha_{\text {before }}=.84, \alpha_{\text {after }}=.89\right)$ that were used in Study 2. As in Study 2, participants completed the same measures before and after the event. 


\subsection{Results}

Descriptive statistics are reported in Table 5. Neither age nor gender predicted any of the dependent variables $(.08<$ all $p$ 's $<.85)$. Again, the expected multivariate effect of naturist activity was found, $F(3,97)=8.42, p<.001, \eta_{2}^{\mathrm{p}}=.21$. After the naturist event, participants reported more positive body-image, $M=3.32$ versus $M=3.55$; $F$ (1, $99)=20.80, p<.001, \eta_{2}^{\mathrm{p}}=.17$, and greater life satisfaction $M=2.74$ versus $M=3.05$; $F(1,99)=11.18, p=.001, \eta_{2}^{\mathrm{p}}=.10$. Participants also reported higher self-esteem after the naturist event than they did before the event, $M=3.42$ versus $M=3.53 ; F$ (1, $99)=3.46, p=.066, \eta_{2}^{\mathrm{p}}=.034$, though this last difference was not quite significant at the 5\% level. Subsequent analyses showed no significant interaction between time and either participant gender, $F(6,188)=1.25, p=.28$ or previous naturist experience, $F(3$, 93) $=2.63, p=.08$.

To conduct mediation analyses, change scores $(\Delta)$ were calculated for each variable by subtracting participants' scores before the naked event from their scores after the naked event. The relationship between $\Delta$ body-image and $\Delta$ life satisfaction, mediated by $\Delta$ selfesteem was investigated using PROCCESS macros (Model 4, with a 95\% confidence interval based on 1000 bootstrap samples; Hayes 2009). The data fit the hypothesised mediated relationship; $\Delta$ body image predicted $\Delta$ self-esteem $(b=.49, p<.0001)$, which predicted $\Delta$ life satisfaction $(b=.70, p<.0001)$. There was no significant direct relationship between $\Delta$ body-image and $\Delta$ life satisfaction $(b=.23, p=.18)$, but there was a significant indirect effect via $\Delta$ self-esteem, $L L C I=.09, U L C I=.74$, p.e. $=.34$ : see Fig. 2. These results indicate that taking part in this event also improved life satisfaction,

Table 5 Means and standard deviations of all variables used in Study 3 according to time

\begin{tabular}{lll}
\hline & Pre-naturist activity & Post-naturist activity \\
\hline Body-image & $3.32(.93)$ & $3.55(.85)$ \\
Self-esteem & $3.42(.91)$ & $3.53(.91)$ \\
Life satisfaction & $2.74(1.13)$ & $3.05(1.15)$ \\
\hline
\end{tabular}

Standard deviations are shown in parentheses

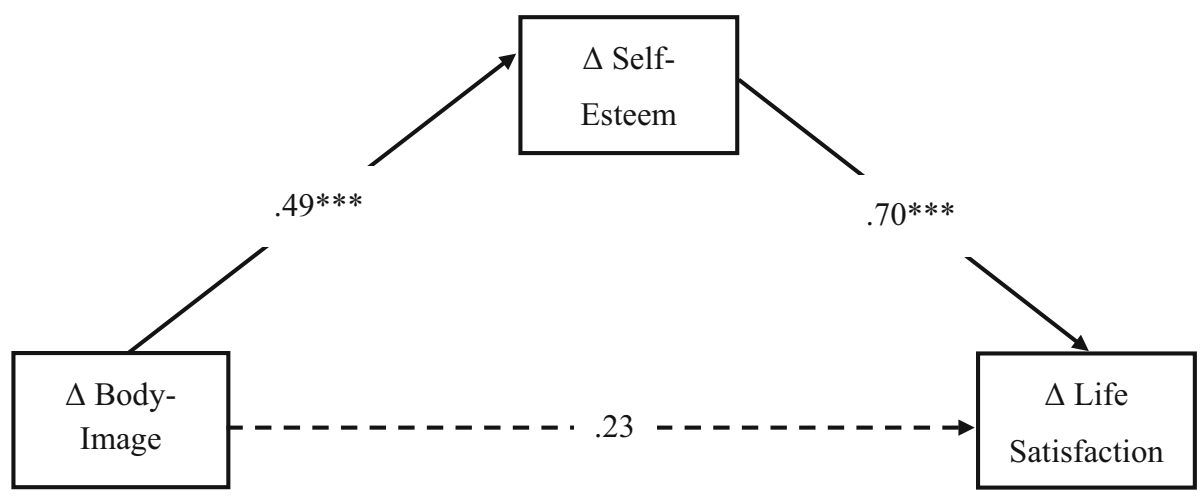

Fig. 2 Relationship between changes in body image and changes in life satisfaction, mediated by changes in self-esteem in Study 3. Note $* p<.05$, **p $<.01$, *** $p<.001$ 
and that this effect was mediated by changes in body image and self-esteem. Again, a possible interpretation is that the communal nudity improved participant's body image, self-esteem and life satisfaction.

\section{Discussion}

Naturist activities contain elements that should promote a more positive body image, higher self-esteem and greater life satisfaction; individuals spend time naked in the company of non-intimate others who typically have non-idealised bodies. However, prior research has not investigated these potential positive effects, or elucidated a model explaining them. This gap was addressed in three studies. A large cross-sectional study (Study 1) found that participants who engaged in more naturist activities also reported greater life satisfaction, and that this relationship was mediated by more positive body image and higher self-esteem. This proposed mediated model fit the data better than a reversed model (in which life satisfaction, self-esteem and body image predicted naturism), was not dependent on gender, and applied more strongly to participants who took part in naturist activity less frequently. Among participants who took part in naturist activities, seeing others naked appeared to be a more important predictor of positive body image than being seen naked by others. Furthermore, in 2 prospective studies of real naturist events (Studies 2 and 3), participation in actual naturist activities resulted in immediate improvements in life satisfaction, an effect that was also mediated by improvements in body image and self-esteem. Below this research is discussed with reference to study design and limitations, suggestions for future research, and implications.

\subsection{Study Design}

This current research adds to the body of knowledge about the effects of naturism with 2 methodologies that have so far been absent in the literature: a cross-sectional comparison of graded variations in naturist activity, and two prospective studies looking at the effects of taking part in actual naturist activity. In terms of practical application, these results are very encouraging. This is the first research to show that individuals do experience increases in positive body-image, self-esteem, and life satisfaction after participating in real naturist activities (Studies 2 and 3) and to suggest mechanisms explaining these effects (Study 1).

Nonetheless, it is important to acknowledge that none of the studies definitively addressed the question of the causal relationship between naturist activity and life satisfaction. A limitation of all cross-sectional research (e.g., Study 1) is that the causal direction of an effect cannot be determined from correlational data, regardless of the sophistication of the statistical techniques (MacCallum and Austin 2000). Studies 2 and 3 do show that the changes in body-image and self-esteem follow participation in naturist activity (rather than preceding it). However Studies 2 and 3 could also be improved upon by including control comparison groups, resulting in genuine randomised controlled trials, rather than prospective before-and-after studies.

That said, these limitations were addressed as far as was possible. In Study 1, the data did not fit a reversed model (in which life satisfaction, self-esteem and body-image predicted naturism), supporting the proposed sequence of effects. This failure of the reversed model was re-confirmed using a subset of participants who took part in fewer naturist activities, which also had the benefit of showing that the failure of the reversed model was 
not simply due to a weak relationship between naturism and body image. Also, the naturist activities used in Studies 2 and 3 had quite similar effects despite being quite different (e.g., one was a charity event and one was not); this further bolsters the hypothesis that the communal nudity itself was the cause of these effects. While randomised controlled trials would be ideal, in studies concerning sensitive activities like public nudity, these designs present some practical difficulties. The methodologies of these three studies compliment each other and provide converging evidence for the positive effects of naturism.

Much social psychological research has been criticized for using non-representative student samples as participants - a limitation which reduces the generalizability of the findings (Henrich et al. 2010; Sears 1986). Study 1 benefits from a large sample of participants (849 individuals) who were diverse in age, gender, and ethnicity, and drawn from the wider public rather than from student samples. Similarly, Studies 2 and 3 used nonstudent individuals taking part in real naturist activities, which bolstered their external validity.

However, there are other ways in which the samples were less representative; In Study 1 there were more men than women, and a much greater proportion of our participants had taken part in naturist activities than expected. It is not clear why this was the case, and likely reflects a strong self-selection bias in the participants, which negatively affects the generalizability of Study 1. Men were similarly overrepresented in Study 3. In Studies 2 and 3 all participants were self-selecting individuals who had voluntarily signed up for naturist activates.

These oddities in the samples were managed, as far as possible, through further analyses. In Study 1 the proposed relationships between naturism, body image, self-esteem, and life satisfaction applied as well to women as they did to men and more strongly to those who participated in naturist activities less frequently, indicating that the findings were likely more applicable to the general public than to those who frequently engage in public nudity. It should similarly be noted that Study 2, which had the most representative participant sample, also had the largest effect sizes. Furthermore, while the use of participants who had already chosen to take part in naturist activities may theoretically reduce the generalizability of Studies 2 and 3, any realistic application of these findings would likely also involve individuals willing to proactively take part in naturist activities.

A final limitation that must be acknowledged is the weak relationship between naturist activity and positive body image in Study $1(b=.08)$. This suggests the potential criticism that the effects of naturism are not practically meaningful, even if they are statistically significant. However, it must also be acknowledged that the effect sizes were much larger in Study $2\left(\eta_{2}^{\mathrm{p}}=.35\right.$ for the multivariate effect; $\eta_{2}^{p}=.26$ for the effect of naturist activity on body image) and in Study $3\left(\eta_{2}^{p}=.21\right.$ for the multivariate effect; $\eta_{2}^{p}=.17$ for the effect of naturist activity on body image).

Also, further analyses in Study 1 revealed that the relationship between naturism and body image was weakest (or absent) for participants who engaged in the most naturist activities (i.e., those least representative of the wider population). For participants who engaged in the least naturist activity (i.e., those most representative of the wider population), the relationship was stronger $(b=.13)$. This suggested that the positive effects of naturism may plateau or taper off past a certain point, similar to the effect of income on wellbeing (Sengupta et al. 2012). This would also imply that those who have never engaged in naturist activities (or those who do so rarely) may have the most to gain from them. 


\subsection{Implications and Future Research}

It was found that seeing others naked was a stronger predictor of positive body image than was being seen naked by others. This answers an important question about the mechanism through which naturist activity might improve body image, and aligns well with recent research indicating that participating in life-drawing lessons also predicts more positive body image (Swami 2015). However, as with the other findings of this current research, this should not be interpreted as evidence of a causal relationship between seeing others naked and positive body image. Future, experimental research could tease apart the effects of seeing others naked versus the effects of being seen naked oneself; both elements were simultaneously present in all the studies reported here. Also, the inclusion of specific measures of perceptions of others' bodies during naturist events could clarify whether it is the variety of apparently acceptable bodies, or the non-idealised nature of the bodies that matters most for challenging accepted idealisations. Similarly, including measures of responses to one's own naked body could help clarify whether positive responses to one's own body are necessary for improving body-image, or whether these effects occur through an anxiety-reduction mechanism (Mathews et al. 2007), in which a lack of negative consequences of nudity is sufficient.

There were no interactions between gender and naturist activity in any of these studies. Nonetheless, it may also be useful to investigate in further depth whether gender alters any of these effects. It is not clear whether women would feel more positively about their own bodies after seeing the non-idealised bodies of men (and vice versa), or whether seeing non-idealised bodies of others of one's own gender is necessary, or more important, for these effects to take place. Similarly, across all three studies most of the participants were White. Non-White individuals sometimes ascribe to different standards of attractiveness (Molloy and Herzberger 1998) and may perhaps benefit most from naturism with others of their own ethnicity. Further research with non-White naturists may provide important insights.

Also, body mass index is an important predictor satisfaction with one's body (Al Sabbah et al. 2009). However, it remains to be seen if the effects of naturism depend on the bodytype of the participant, or whether naturism is equally beneficial, regardless of how much or little one resembles idealised body-types. In a similar vein, this research used apparently non-clinical samples of participants to investigate the relationship between naturism, body image, self-esteem, and life satisfaction. The relationships between these variables may be different in participants with clinical levels of body dissatisfaction, such as those with eating disorders (Brannan and Petrie 2011). Thus, even if naturism has positive effects on sub-clinical levels of negative body-image, it should not be assumed that it would have similar effects on clinical populations. Indeed, given the somewhat modest strength of the relationships found in these studies, it seems very important to investigate the moderators of naturism's potential effects, and the conditions under which it would be most useful.

\section{Concluding Remarks}

Naturism remains unconventional, and is sometimes seen as psychologically or sexually unhealthy, even by mental health professionals (Negy 2004). However, in recent decades, a significant body of research has failed to find negative effects of naturism on either adults or children (Okami 1995). Perhaps unsurprisingly, an increasing number of people are 
taking part in naturist activities and the focus of some research has shifted toward the potential positive effects of naturism. These current findings add meaningfully to the scant empirical literature on the effects of naturism, and are the first to provide evidence for specific mechanisms behind naturism's effects. This research should be considered the suggestive beginning of a body of research, rather than a definitive conclusion of one. Nonetheless, it should not only be interesting to those hoping to academically understand the factors affecting our perceptions of our bodies, but also to public health practitioners who may come to see naturism as a cheap, almost universally available means of promoting healthy body-image, positive self-esteem and overall life satisfaction. As more people participate in clothing-optional activities, these potential benefits of naturism are worth exploring.

Acknowledgements The author would like to thank Mr. Andrew Welch for his invaluable assistance in conducting these studies, particularly in gaining access to these participants.

Open Access This article is distributed under the terms of the Creative Commons Attribution 4.0 International License (http://creativecommons.org/licenses/by/4.0/), which permits unrestricted use, distribution, and reproduction in any medium, provided you give appropriate credit to the original author(s) and the source, provide a link to the Creative Commons license, and indicate if changes were made.

\section{References}

Abraczinskas, M., Fisak, B., \& Barnes, R. D. (2012). The relation between parental influence, body image, and eating behaviors in a nonclinical female sample. Body Image, 9(1), 93-100. doi:10.1016/j.bodyim. 2011.10.005.

Acun-Kapikiran, N., Korukcu, Ö., \& Kapikiran, Ş. (2014). The relation of parental attitudes to life satisfaction and depression in early adolescents: The mediating role of self-esteem. Educational Sciences: Theory \& Practice, 14(4), 1246-1253. doi:10.12738/estp.2014.4.2137.

Agliata, D., \& Tantleff-Dunn, S. (2004). The impact of media exposure on males body image. Journal of Social and Clincical Psychology. doi:10.1521/jscp.23.1.7.26988.

Al Sabbah, H., Vereecken, C. A., Elgar, F. J., Nansel, T., Aasvee, K., Abdeen, Z., et al. (2009). Body weight dissatisfaction and communication with parents among adolescents in 24 countries: International crosssectional survey. BMC Public Health, 9, 52-62. doi:10.1186/1471-2458-9-52.

Ålgars, M., Santtila, P., Jern, P., Johansson, A., Westerlund, M., \& Sandnabba, N. K. (2011). Sexual body image and its correlates: A population-based study of finnish women and men. International Journal of Sexual Health, 23(1), 26-34. doi:10.1080/19317611.2010.509692.

Ashburn-Nardo, L., Monteith, M. J., Arthur, S. A., \& Bain, A. (2007). Race and the psychological health of African Americans. Group Processes \& Intergroup Relations, 10(4), 471-491. doi:10.1177/ 1368430207081536.

Avalos, L., Tylka, T. L., \& Wood-Barcalow, N. (2005). The body appreciation scale: Development and psychometric evaluation. Body Image, 2(3), 285-297. doi:10.1016/j.bodyim.2005.06.002.

Brannan, M. E., \& Petrie, T. A. (2011). Psychological well-being and the body dissatisfaction-bulimic symptomatology relationship: An examination of moderators. Eating Behaviors, 12(4), 233-241. doi:10.1016/j.eatbeh.2011.06.002.

British Naturism: What is Naturism? (2015, October 09). Retrieved from http://www.bn.org.uk/ aboutnaturism/

Carr-Gomm, P. (2012). A brief history of nakedness. London: Reaktion Books.

Cooper, D. (2011). Theorising nudist equality: An encounter between political fantasy and public appearance. Antipode, 43(2), 326-357.

Deschenes, S. (2016, January 4). The official INF-FNI definition of naturism. Retrieved from http://www. inffni.org/content/download/28259/1110928/file/OfficialINF-FNIDefinitionOfNaturism.pdf

Dieleman, H. (2008). Sustainability art and reflexivity: Why artists and designers may become key change agents in sustainability. In S. Kagan \& K. Kenison (Eds.), Sustainability: A new frontier for the arts and cultures (pp. 108-146). Vas. 
Diener, E., Emmons, R., Larsen, J., \& Griffin, S. (1985). The satisfaction with life scale. Journal of Personality Assessmemt, 49(1), 71-75. doi:10.1207/s15327752jpa4901_13.

Engeln-Maddox, R. (2005). Cognitive responses to idealized media images of women: The relationship of social comparison and critical processing to body image disturbance in college women. Journal of Social and Clinical Psychology, 24(8), 1114-1138. doi:10.1521/jscp.2005.24.8.1114.

Evans-Lacko, S., Malcolm, E., West, K., Rose, D., London, J., Rüsch, N., et al. (2013). Influence of Time to Change's social marketing interventions on stigma in England 2009-2011. British Journal of Psychiatry, 202(SUPPL.55), s77-s88.

Fritz, M. S., \& Mackinnon, D. P. (2007). Required sample size to detect the mediated effect. Psychological Science, 18(3), 233-239. doi:10.1111/j.1467-9280.2007.01882.x.

Fryer, R. G., Jr., \& Levitt, S. D. (2004). Understanding the Black-White test score gap in the first two years of school. Review of Economics and Statistics, 86, 447-464.

Grabe, S., Ward, L. M., \& Hyde, J. S. (2008). The role of the media in body image concerns among women: A meta-analysis of experimental and correlational studies. Psychological Bulletin, 134(3), 460-476. doi:10.1037/0033-2909.134.3.460.

Green, L. R. (2001). Hiding behind nakedness on the nude beach. Australian Journal of Communication, $28(3), 1-10$.

Hayes, A. F. (2009). Beyond Baron and Kenny: Statistical mediation analysis in the new millennium. Communication Monographs, 76(4), 408-420. doi:10.1080/03637750903310360.

Henrich, J., Heine, S. J., \& Norenzayan, A. (2010). The weirdest people in the world? The Behavioral and Brain Sciences, 33(2-3), 61-83. doi:10.1017/S0140525X0999152X.

Herbozo, S., \& Thompson, J. K. (2006). Appearance-related commentary, body image, and self-esteem: Does the distress associated with the commentary matter? Body Image, 3(3), 255-262. doi:10.1016/j. bodyim.2006.04.001.

Hesketh, K., Wake, M., \& Waters, E. (2004). Body mass index and parent-reported self-esteem in elementary school children: Evidence for a causal relationship. International Journal of Obesity and Related Metabolic Disorders, 28(10), 1233-1237. doi:10.1038/sj.ijo.0802624.

Ipsos-Mori. (2011). 2011 Attitudes to Nudity Omnibus Research. London: Author.

Kang, S.-M., Shaver, P. R., Sue, S., Min, K.-H., \& Jing, H. (2003). Culture-specific patterns in the prediction of life satisfaction: Roles of emotion, relationship quality, and self-esteem. Personality and Social Psychology Bulletin, 29(12), 1596-1608. doi:10.1177/0146167203255986.

Kostanski, M., \& Gullone, E. (1998). Adolescent body image dissatisfaction: Relationships with selfesteem, anxiety, and depression controlling for body mass. Journal of Child Psychology and Psychiatry and Allied Disciplines, 39(2), 255-262. doi:10.1111/1469-7610.00319.

Lewis, R. J., \& Janda, L. H. (1988). The relationship between adult sexual adjustment and childhood experiences regarding exposure to nudity, sleeping in the parental bed, and parental attitudes toward sexuality. Archives of Sexual Behavior, 17(4), 349-362.

Liechty, J. M. (2010). Body image distortion and three types of weight loss behaviors among nonoverweight girls in the United States. Journal of Adolescent Health, 47(2), 176-182. doi:10.1016/j.jadohealth. 2010.01.004.

MacCallum, R. C., \& Austin, J. T. (2000). Applications of structural equation modeling in psychological research. Annual Review of Psychology, 51, 201-226. doi:10.1146/annurev.psych.51.1.201.

Mason, K. (2015, May). Streakers set to strip off for naked wildlife park run. Doncaster Free Press, pp. 57-60. Retrieved from http://www.doncasterfreepress.co.uk/news/streakers-set-to-strip-off-fornaked-wildlife-park-run-1-7244405.

Mathews, A., Ridgeway, V., Cook, E., \& Yiend, J. (2007). Inducing a benign interpretational bias reduces trait anxiety. Journal of Behavior Therapy and Experimental Psychiatry, 38(2), 225-236. doi:10.1016/ j.jbtep.2006.10.011.

McCreary, D. R., \& Sasse, D. K. (2000). Exploring the drive for muscularity in adolescent boys and girls. Journal of American College Health, 48, 297-304. doi:10.1080/07448480009596271.

Mclaren, L., Kuh, D., Hardy, R., \& Gauvin, L. (2004). Positive and negative body-related comments and their relationship with body dissatisfaction in middle-aged women. Psychology \& Health, 19(2), 261-272. doi:10.1080/0887044031000148246.

Molloy, B. L., \& Herzberger, S. D. (1998). Body Image and self-esteem: A comparison of AfricanAmerican and Caucasian women. Sex Roles, 38(7/8), 631-643.

Navarro, R. L., Ojeda, L., Schwartz, S. J., Piña-Watson, B., \& Luna, L. L. (2014). Cultural self, personal self: Links with life satisfaction among Mexican American college students. Journal of Latina/o Psychology, 2(1), 1-20. doi:10.1037/lat0000011. 
Negy, C. (2004). Therapy with dissimilar clients: Issues to consider along this road more traveled. In C. Negy (Ed.), Cross-cultural psychotherapy: Toward a critical understanding of diverse clients (pp. 3-22). Reno, NV: Bent Tree Press.

Negy, C., \& Winton, S. (2008). A comparison of pro- and anti-nudity college students on acceptance of self and of culturally diverse others. Journal of Sex Research, 45(3), 287-294. doi:10.1080/ 00224490802204464.

O'Reilley, C. (2015). It's all good nudes: Get naked; how getting starkers can keep you healthy. The Sun, 1-21. Retrieved from http://www.thesun.co.uk/sol/homepage/features/6615651/The-health-benefits-ofgoing-nude.html.

Oishi, S., Diener, E. F., Lucas, R. E., \& Suh, E. M. (1999). Cross-cultural variations in predictors of life satisfaction: Perspectives from needs and values. Personality and Social Psychology Bulletin, 25(8), 980-990. doi:10.1007/978-90-481-2352-0.

Okami, P. (1995). Childhood exposure to parental nudity, parent co-sleeping and "primal scenes": A review of clinical opinion and empirical evidence. The Journal of Sex Research, 32(1), 51-63.

Okami, P., Olmstead, R., Abramson, P. R., \& Pendleton, L. (1998). Early childhood exposure to parental nudity and scenes of parental sexuality ('primal scenes'): An 18-year longitudinal study of outcome. Archives of Sexual Behavior, 27(4), 361-384.

Oleinick, M. S., Bahn, A. K., Eisenberg, L., \& Lilienfeld, A. M. (1966). Early socialization experiences and intrafamilial environment: A study of psychiatric outpatient and control group children. Archives of General Psychiatry, 15(4), 344-353.

Olivardia, R., Pope, H. G. J., Borowiecki, J. J. I., \& Cohane, G. H. (2004). Biceps and body image: The relationship between muscularity and self-esteem, depression, and eating disorder symptoms. Psychology of Men \& Masculinity, 5(2), 112-120. doi:10.1037/1524-9220.5.2.112.

Paradise, A. W., \& Kernis, M. H. (2002). Self-esteem and psychological well-being: Implications of fragile self-esteem. Journal of Social and Clinical Psychology, 21(4), 345-361.

Park, H.-J., Lee, D.-G., \& Yang, N. M. (2014). Life satisfaction in middle-aged Koreans: Mediating effects of domain-specific self-esteem satisfaction, and sex differences. Psychological Reports, 115(1), 213-227. doi:10.2466/07.10.PR0.115c11z4.

Pelegrini, A., \& Petroski, E. (2010). The association between body dissatisfaction and nutritional status in adolescents. Human Movement, 11(1), 51-57. doi:10.2478/v10038-010-0001-7.

Pucher, J., Buehler, R., \& Seinen, M. (2011). Bicycling renaissance in North America? An update and reappraisal of cycling trends and policies. Transportation Research Part A: Policy and Practice, 45(6), 451-475. doi:10.1016/j.tra.2011.03.001.

Re, D., Coetzee, V., \& Xiao, D. (2011). Viewing heavy bodies enhances preferences for facial adiposity. Journal of Evolutionary Psychology, 9(4), 295-308.

Rosenberg, M. (1965). Society and the adolescent self-image. Princeton, NJ: Princeton University Press.

Sears, D. O. (1986). College sophomores in the laboratory: Influences of a narrow data base on social psychology's view of human nature. Journal of Personality and Social Psychology, 51(3), 515-530. doi:10.1037/0022-3514.51.3.515.

Sengupta, N. K., Osborne, D., Houkamau, C. A., Hoverd, W. J., Wilson, M. S., Greaves, L. M., et al. (2012). How much happiness does money buy? Income and subjective well-being in New Zealand. New Zealand Journal of Psychology, 41(2), 21-34.

Smith, H. W. (1980). Does shedding one's clothes imply shedding one's culture? A cross-cultural test of nudism claims. International Review of Modern Sociology, 10, 255-268. doi:10.1007/BF00987137.

Smith, G., \& King, M. (2009). Naturism and sexuality: Broadening our approach to sexual wellbeing. Health and Place, 15(2), 439-446. doi:10.1016/j.healthplace.2008.08.002.

Smith, D. C., \& Sparks, W. (1986). The naked child: Growing up without shame. Los Angeles: Elysium Growth Press.

Story, M. D. (1979). Factors associated with more positive body self-concepts in preschool children. The Journal of Social Psychology, 108(1), 49-56. doi:10.1080/00224545.1979.9711960.

Story, M. D. (1984). Comparisons of body self-concept between social nudists and nonnudists. The Journal of Psychology: Interdiciplinary and Applied, 118(1), 99-112.

Strand, S. (2012). The White British-Black Caribbean achievement gap: Tests, tiers and teacher expectations. British Educational Research Journal, 38(1), 75-101. doi:10.1080/01411926.2010.526702.

Striegel-Moore, R. H., Silberstein, L. R., \& Rodin, J. (1986). Toward an understanding of risk factors for bulimia. American Psychologist, 41, 246-263. doi:10.1037/0003-066X.41.3.246.

Swami, V. (2015). Illustrating the body: Cross-sectional and prospective investigations of the impact of life drawing sessions on body image. Psychiatry Research, 235, 128-132. doi:10.1016/j.psychres.2015.11. 034. 
Taschler, M., \& West, K. (2016). Contact with counter-stereotypical women predicts less sexism, less rape myth acceptance, less intention to rape (in men) and less projected sexualisation of rape (in women). Sex Roles. doi:10.1007/s11199-016-0679-x.

Voci, A., \& Hewstone, M. (2003). Intergroup contact and prejudice toward immigrants in Italy: The mediational role of anxiety and the moderational role of group salience. Group Processes \& Intergroup Relations, 6(1), 37-54. doi:10.1177/1368430203006001011.

West, K., \& Hewstone, M. (2012). Culture and contact in the promotion and reduction of anti-gay prejudice: Evidence from Jamaica and Britain. Journal of Homosexuality, 59(1), 44-66.

West, K., Hewstone, M., \& Lolliot, S. (2014). Intergroup contact and prejudice against people with schizophrenia. The Journal of Social Psychology, 154(3), 217-232. 